\title{
Peramalan Jumlah Penumpang di Bandara Internasional Juanda Menggunakan Metode ARIMA, Regresi Time Series, TBATS
}

\author{
1Silviatul Hasanah \\ ${ }^{1}$ Fakultas Ilmu Tarbiyah dan Keguruan, Manajemen Pendidikan Islam, Universitas Islam Negeri \\ Islam Walisongo Semarang \\ silviatulh@walisongo.ac.id
}

\begin{tabular}{l} 
ARTICLE INFO \\
\hline Article History: \\
Received $\quad: 18-03-2019$ \\
Revised $: 10-05-2019$ \\
Accepted $: 25-05-2019$ \\
Online : 30-05-2019 \\
Keywords: \\
Arima: Regresi Time \\
Series; RMSE; TBATS
\end{tabular}

Series; RMSE; TBATS

\begin{abstract}
Abstract: One of the busiest airports in Indonesia managed by PT. Angkasa Pura I is Juanda International Airport. Besides, Juanda International Airport is also one of the gateways for the Indonesian state to other countries. The number of passengers at the departure terminal at Juanda International Airport from 2012 to 2013, both domestic and international routes, has increased by about 6.74\%. Meanwhile, the arrival terminal experienced an increase of about $8.31 \%$. From 2013 to 2014 the departure route decreased by 2.51\%. Meanwhile, the arrival route decreased by 1.99\%. In 2014 to 2015 the departure route decreased by $11.31 \%$. Meanwhile, the arrival route decreased by $0.78 \%$. There is an increase and decrease in the number of passengers at Juanda International Airport, it is necessary to research forecasting the number of passengers at Juanda International Airport, both from domestic routes and international routes. The purpose of this study is to balance number of passengers and number of flights in the future with the availability of the number of aircraft and airport capacity. The data used is data on the number of passengers each month at Juanda International Airport. Where the data was obtained from PT. Angkasa Pura I (Persero). The criteria for selecting the best model based on the RMSE value shows that the best model selected by the ARIMA model has 14 routes, while the selected Time Series Regression model has 9 routes and the selected TBATS model has 7 routes.

Abstrak: Salah satu bandara tersibuk di Indonesia yang diolah PT. Angkasa Pura I adalah Bandara Internasional Juanda. Selain itu, Bandara Internasional Juanda juga merupakan salah satu pintu gerbang negara Indonesia menuju negara-negara lain. Jumlah penumpang di terminal keberangkatan Bandara Internasional Juanda dari tahun 2012 hingga tahun 2013 baik rute domestik maupun internasional mengalami peningkatan sekitar 6,74\%. Sedangkan di terminal kedatangan mengalami kenaikan sekitar 8,31\%. Pada tahun 2013 hingga tahun 2014 pada rute keberangkatan mengalami penurunan sebesar $2,51 \%$. Sedangkan pada rute kedatangan mengalami penurunan sebesar 1,99\%.Pada tahun 2014 hingga tahun 2015 pada rute keberangkatan mengalami penurunan sebesar $11,31 \%$. Sedangkan pada rute kedatangan mengalami penurunan sebesar 0,78\%. Adanya kenaikan dan penurunan jumlah penumpang di Bandara Internasional Juanda, maka perlu diadakan penelitian mengenai peramalan jumlah penumpang di Bandara Internasional Juanda, baik dari rute domestik maupun rute internasional. Tujuan dari penelitian ini adalah untuk menyeimbangkan jumlah penumpang dan jumlah penerbangan pada masa mendatang dengan ketersediaan jumlah pesawat dan kapasitas bandar udara.Data yang digunakan adalah data jumlah penumpang tiap bulan di Bandara Internasional Juanda. Dimana data tersebut diperoleh dari PT. Angkasa Pura I (Persero). Kriteria pemilihan model terbaik berdasarkan nilai RMSE menunjukkan bahwa Model terbaik yang terpilih model ARIMA terdapat 14 rute sedangkan yang terpilih model Regresi Time Series terdapat 9 rute dan yang terpilih model TBATS terdapat 7 rute.
\end{abstract}




\section{A. LATAR BELAKANG}

Bandara Internasional Juanda merupakan bandara yang dioperasikan oleh PT. Angkasa Pura I. Bandara tersebut terletak di Kecamatan Sedati, Kabupaten Sidoarjo, 20 km sebelah selatan Kota Surabaya. Berdasarkan pergerakan pesawat dan penumpang, Bandara Internasional Juanda merupakan bandara tersibuk kedua di Indonesia setelah Bandara Internasional Soekarno-Hatta. Menurut hasil survei online The Guide to Sleeping in Airports (2016), Bandara Internasional Juanda merupakan bandara yang berada pada peringkat ke-26 dari 30 bandara terbaik di Asia pada tahun 2015 dan Menurut penilaian Airport Service Quality (ASQ) pada periode Oktober-Desember 2014 Bandara Internasional Juanda menempati peringkat ke-10 dari 31 bandara di dunia yang berada dalam kategori ketiga pada kategori Best Airport by Size (Airports Council Internasional, 2014).

Jumlah penumpang di terminal keberangkatan Bandara Internasional Juanda baik rute domestik maupun internasional dari tahun 2012 hingga tahun 2015 mengalami kenaikan dan penurunan. Adanya kenaikan dan penurunan jumlah penumpang di terminal keberangkatan Bandara Internasional Juanda, maka perlu diadakan penelitian mengenai peramalan jumlah penumpang di Bandara Internasional Juanda, baik dari rute domestik maupun rute internasional. Hal ini bertujuan untuk menyeimbangkan jumlah penumpang dan jumlah penerbangan pada masa mendatang dengan ketersediaan jumlah pesawat dan kapasitas bandar udara (Alin, Mihai, Marieta, \& Cosmin, 2019). Beberapa penelitian telah dilakukan untuk meramalkan jumlah penumpang pesawat diantaranya Suryani, Chou, \& Chen meramalkan jumlah penumpang pesawat, dimana hasil yang didapat adalah jumlah penumpang pesawat dipengaruhi oleh harga tiket pesawat, tingkat pelayanan bandara, PDB, jumlah penduduk dan jumlah penerbangan per hari (Suryani, Chou, \& Chen, 2010). Penelitian serupa juga dilakukan oleh Tsui, Balli, Gilbey, \& Gow (2014) yang meramalkan jumlah penumpang pesawat di Bandara Internasional Hong Kong pada tahun 2015 dengan menggunakan metode Seasonal ARIMA (Sarima) dan ARIMAX, dimana kedua metode ini mendapatkan hasil peramalan jumlah penumpang yang stabil. Peramalan menggunakan metode ARIMA dan variasi kalender pernah dilakukan oleh Wulandari (2016) dengan kesimpulan bahwa dua metode tersebut merupakan metode yang terbaik untuk meramalkan inflasi. Penelitian lain juga pernah dilakukan oleh Xie, Wang, \& Lai (2014) yang meramalkan jumlah penumpang di Bandara Internasional Hong Kong, diperoleh hasil bahwa pendekatan metode hybrid lebih baik dari kedua metode individu, sehingga metode hybrid merupakan alat yang menjanjikan untuk memprediksi seri waktu yang kompleks dengan high volatility dan irregularity.

Berdasarkan paparan di atas, maka akan dilakukan penelitian mengenai peramalan jumlah penumpang di Bandara Internasional Juanda pada rute domestik dan internasional menggunakan metode TBATS (Trigonometric exponential smoothing state space model with Box-Cox transformation, ARMA errors, Trend, and Seasonal components). Metode TBATS digunakan karena memiliki banyak kelebihan yaitu dapat mengakomodasi terjadinya pola musiman yang kompleks seperti pola musiman non-integer, efek dual kalender, dan pola musiman non-nested. Selain itu juga dapat mengakomodasi terjadinya trend, kasus-kasus non-linearitas, serta pemodelan error ARMA. Metode TBATS merupakan metode gabungan dari metode ARIMA dan metode regresi time series. Adanya metode gabungan dikarenakan hasil dari M3-Competition yang ketiga menyatakan bahwa penggabungan dari beberapa metode individu peramalan akan meningkatkan akurasi hasil peramalan. Sehingga dalam penelitian ini, peneliti ingin membandingkan metode individu dan metode gabungan (hibrida), dimana metode individu yang digunakan adalah metode ARIMA dan regresi time series, sedangkan metode gabungan (hibrida) yang 
digunakan adalah metode TBATS. Pembandingan metode ini digunakan untuk mengetahui apakah metode gabungan (hibrida) jauh lebih baik dari pada metode individu (Makridakis \& Hibon, 2000). Penelitian sebelumnya mengenai metode TBATS pernah dilakukan oleh Kusumawati dengan melakukan penelitian mengenai pemodelan beban sistem listrik Jawa-Bali dengan hasil bahwa pemodelan TBATS dengan memasukkan Hari Raya Idul Fitri sebagai efek musiman tetap memiliki hasil yang lebih baik dibandingkan pemodelan TBATS tanpa memasukkan Hari Raya Idul Fitri sebagai efek musiman tetap karena diperoleh nilai RMSE dan MAPE yang lebih kecil (Kusumawati, 2015).

Pada penelitian ini, hasil dari pemodelan ARIMA, Regresi Time Series dan TBATS dibandingkan untuk mendapatkan model terbaik berdasarkan nilai RMSE. Pada penelitian ini diharapkan dapat memberikan informasi bagi pihak PT. Angkasa Pura I berapa jumlah maskapai yang dibutuhkan untuk penerbangan pada masa mendatang.

\section{B. METODE PENELITIAN}

Metode yang digunakan dalam penelitian ini adalah data sekunder yang merupakan data jumlah penumpang pesawat per bulan di Bandara Internasional Juanda dari tahun 1999-2015 yang diperoleh dari PT. Angkasa Pura I (Persero). Data penumpang pesawat yang digunakan dipengaruhi oleh variasi kalender Hari Raya Idul Fitri. Variabel prediktor

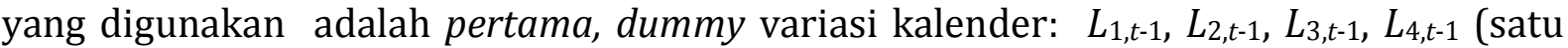
bulan sebelum Idul Fitri); $L_{1, t}, L_{2, t}, L_{3, t}, L_{4, t}$ (minggu Hari Raya Idul Fitri); $L_{1, t+1}, L_{2, t+1}, L_{3, t+1}$, $L 4, t+1$ (satu bulan setelah Idul Fitri). Kedua, dummy tren: $t$ (tren jumlah penumpang pesawat); $D_{1}$ (dummy periode); dan $t D_{2}$ (dummy periode dan tren). Ketiga, dummy musiman (bulan) sebagai berikut: $M_{1, t}, M_{2, t}, \ldots, M_{12, t}$ : Bulan Januari, Februari, ..., Desember (Lee, Suhartono, \& Hamzah, 2010).

\section{Langkah Analisis}

Langkah analisis yang akan dilakukan dalam penelitian ini adalah sebagai berikut (1) Mendeskripsikan karakteristik data penumpang pesawat di Bandara Internasional Juanda; (2) Membagi data menjadi data in sample dan out sample. Data in sample dimulai dari periode 1 Januari 1999 sampai 31 Desember 2014 dan data out sample dimulai dari periode 1 Januari 2015 sampai 31 Desember 2015; (3) Menentukan model regresi time series pada data jumlah penumpang pesawat di Bandara Internasional Juanda; (4) Menentukan model ARIMA pada data jumlah penumpang pesawat di Bandara Internasional Juanda; (5) Menentukan model TBATS pada data jumlah penumpang pesawat di Bandara Internasional Juanda; (6) Membandingkan akurasi peramalan pada model Regresi Time Series, ARIMA, dan TBATS berdasarkan kriteria MAPE dan RMSE dan menarik kesimpulan; (7) Melakukan peramalan berdasarkan model yang telah terpilih berdasarkan kriteria MAPE dan RMSE (Aczel \& Sounderpandian, 2008).

\section{Model Autoregressive Integrated Moving Average (ARIMA)}

Model ARMA (Autoregressive Moving Average) merupakan model peramalan yang termasuk dalam kelompok linear. Model ARMA $(p, q)$ diaplikasikan pada data time series dengan mean dan variance konstan. Secara statistik model ARMA $(p, q)$ dapat ditulis sebagai berikut.

$$
\phi_{p}(B) \dot{Y}_{t}=\theta_{q}(B) a_{t}
$$

Bila data mengandung differencing orde $d$ maka akan menjadi model ARIMA (Autoregressive Integreted Moving Average). Sehingga secara statistik model ARIMA $(p, d, q)$ dapat ditulis sebagai berikut (Wei, 2006).

$$
\phi_{p}(B)(1-B)^{d} Y_{t}=\theta_{0}+\theta_{q}(B) a_{t}
$$

Prosedur yang digunakan dalam pemodelan ARIMA adalah prosedur ARIMA BoxJenkins. Prosedur ini memiliki 4 tahapan, yaitu identifikasi model, estimasi dan 
signifikansi parameter, cek diagnosa, dan peramalan. Estimasi parameter model ARIMA dapat dilakukan menggunakan beberapa metode yaitu metode moment, conditional least square, maximum likelihood dan unconditional least square. Pemodelan linier, motode conditional least square (CLS) merupakan metode yang paling sering digunakan dalam estimasi parameter. Algoritma metode conditional least square (CLS) dijelaskan di buku Cryer, J. D., \& Chan, K (2008).

\section{Model Regresi Time Series}

Regresi time series merupakan variabel dependent $\left(Y_{t}\right)$ yang bergantung dengan fungsi waktu $t$. Kecenderungan adanya pola tren pada time series mempengaruhi dalam regresi time series. Model tersebut dapat ditulis sebagai berikut.

$$
Y_{t}=T R_{t}+a_{t}
$$

dimana, $Y_{t}$ adalah variabel dependen pada waktu ke-t, $T R_{t}$ adalah tren pada waktu ke-t, dan $a_{t}$ adalah residual pada waktu ke-t yang diasumsikan i.i.d.N $\left(0, \sigma^{2}\right)$ untuk $\mathrm{t}=1,2, \ldots, \mathrm{n}$ (Bowerman \& O'Connell, 1993).

\section{Model TBATS}

Model TBATS (Trigonometric exponential smoothing state space model with Box-Cox transformation, ARMA errors, Trend and Seasonal components) merupakan pengembangan dari model BATS (Exponential smoothing state space model with Box-Cox transformation, ARMA errors, Trend and Seasonal components). Persamaan dari model TBATS sebagai berikut (Livera, Hyndman, \& Snyder, 2011).

$$
y_{t}^{(\omega)}=\left\{\begin{array}{c}
\frac{y_{t}^{(\omega)}-1}{\omega}, \omega=0 \\
\log \left(y_{t}\right), \omega \neq 0
\end{array}\right.
$$

Salah satu asumsi yang harus dipenuhi adalah distribusi normal. Pengujian distribusi normal dilakukan menggunakan uji Kolmogorov-Smirnov (Daniel, 2000).

\section{Peramalan}

Setelah data memenuhi asumsi pada pegujian diagnosa, langkah selanjutnya adalah melakukan peramalan untuk menghitung nilai-nilai ramalan $l$ tahap ke depan. Persamaan untuk menghitung taksiran ramalan titik pada waktu $n+l$ adalah sebagai berikut (Wei, 2006).

\section{Pemilihan Model Terbaik}

$$
E\left(Y_{n+l} \mid Y_{n}, Y_{n-1}, \ldots, Y_{1}\right)=\hat{Y}_{n}(l) .
$$

Pemilihan model terbaik dapat dilihat dari 2 kriteria yaitu Root Mean Square Error (RMSE) dan Mean Absolute Percentage Error (MAPE). Pada data outsample kriteria pemilihan model terbaik menggunakan nilai RMSE dan MAPE. Semakin kecil nilai RMSE dan MAPE maka kesalahan peramalan dari model yang dihasilkan juga semakin kecil. Berikut ini rumus RMSE dan MAPE.

$$
R M S E=\sqrt{M S E}=\sqrt{\frac{1}{n} \sum_{t=1}^{n}\left(y_{t}-\hat{y}_{t}\right)^{2}} \quad \text { MAPE }=\frac{\sum_{t=1}^{n}\left|\left(y_{t}-\hat{y}_{t}\right) / y_{t}\right|}{n} \times 100, y_{t} \neq 0
$$

\section{HASIL DAN PEMBAHASAN}

\section{Pemodelan Penumpang Pesawat dengan Metode ARIMA}

Pada pemodelan ARIMA Box-Jenkins terdapat 4 tahapan yaitu identifikasi model, estimasi dan signifikansi parameter, cek diagnosa, dan peramalan. Tahapan pertama ialahidentifikasi model (stasioneritas dalam varians dan mean). Pengujian stasioneritas dalam varians menggunakan transformasi Box-Cox. Pada pengujian tersebut semua data 
kedatangan dan keberangkatan penumpang baik domestik maupun internasional kecuali, data rute Batam dan Bandar Sri Begawan menghasilkan lambda tidak sama dengan 1, batas atas dan bawah tidak memuat nilai 1. Sehingga perlu dilakukan transformasi BoxCox karena tidak stasioner dalam varians. Apabila data tidak stasioner dalam mean maka dilakukan differencing. Setelah data memenuhi asumsi stasioner dalam varians dan mean, maka tahap selanjutnya adalah menentukan orde $p$ dan $q$ untuk menduga model ARIMA. Berdasarkan model ARIMA yang telah diperoleh dilakukan estimasi dan pengujian parameter. Pada pengujian tersebut diketahui bahwa semua parameter sudah signifikan yang ditunjukkan oleh $p$-value kurang dari $\alpha 0,05$.

Tahap selanjutnya setelah mengetahui parameter yang signifikan adalah cek diagnosa (menguji asumsi residual white noise dan distribusi normal). Pengujian residual ini bertujuan untuk mengetahui apakah residual dari data sudah independen dan berdistribusi normal. Pada semua data kedatangan dan keberangkatan penumpang baik rute domestik maupun internasional telah memenuhi asumsi residual white noise. Sedangkan pada pengujian asumsi residual berdistribusi normal ada beberapa model yang belum terpenuhi karena nilai $p$-value kurang dari $\alpha 0,05$. Ketidaknormalan pada model ARIMA bisa diakibatkan oleh adanya outlier. Outlier pada data penumpang di Bandara Internasional Juanda diduga karena adanya efek variasi kalender. Sehingga tahap selanjutnya dilakukan pemodelan Regresi Time Series dengan efek variasi kalender.

\section{Pemodelan Penumpang Pesawat dengan Metode Regresi Time Series}

Pada pemodelan Regresi Time Series tahap pertama yang dilakukan adalah pengujian asumsi residual yang meliputi white noise dan uji distribusi normal. Apabila asumsi residual white noisetidak terpenuhi maka lag yang signifikan dimasukkan dalam model dan diregresikan kembali, sedangkan apabila asumsi distribusi normal tidak terpenuhi dilakukan deteksi outlier. Pada pengujian asumsi tersebut diketahui bahwa semua data telah memenuhi asumsi residual white noise. Sedangkan jika dilihat dari asumsi residual berdistribusi normal masih terdapat beberapa rute yang belum memenuhi asumsi ditribusi normal. Langkah selanjutnya adalah melakukan estimasi dan pengujian signifikansi parameter menggunakan metode Backward Elimination.

\section{Pemodelan Penumpang Pesawat dengan Metode TBATS}

Pemodelan TBATS data kedatangan penumpang rute Denpasar diperoleh hasil yaitu TBATS $(0,328,\{0,0\}, 1,\{12,4\})$.Pada pemodelan ini 0,328 merupakan besarnya transformasi Box-Cox untuk data pada model dan korelasi residual ditunjukkan dengan orde ARMA $(0,0)$. Nilai 1 menunjukkan koefisien dari parameter damping trend dalam model. Selanjutnya $\{12,4\}$ menunjukkan periode musiman dan jumlah harmoni. Hasil dari pemodelan rute Denpasar dapat dilihat pada Tabel 1.

Tabel 1. Koefisien Model TBATS pada Rute Kedatangan Denpasar

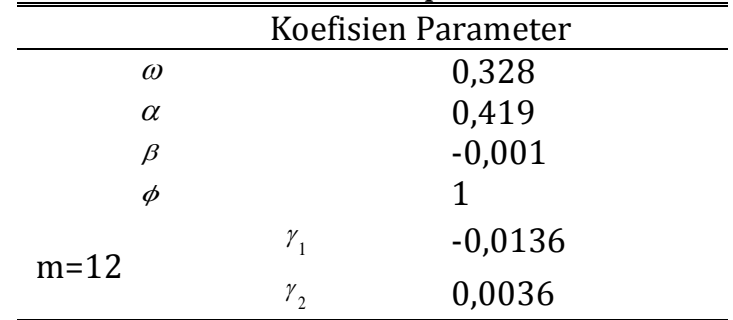

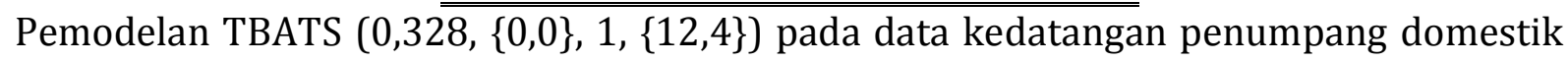
rute Denpasar dapat dituliskan sebagai berikut.

$$
y_{1, t}^{(0,328)}=l_{t-1}+b_{t-1}+s_{t-m_{1}}^{(1)}+d_{t}
$$




\section{Perbandingan Model ARIMA, Regresi Time Series, dan TBATS}

Model yang sudah didapat yaitu model ARIMA, Regresi Time Series, dan TBATS dibandingkan menggunakan kriteria kebaikan model RMSE.Berikut ini perbandingan nilai RMSE pada rute kedatangan penumpang domestik.

Tabel 2. Perbandingan Nilai RMSE pada Rute Kedatangan Penumpang Domestik

\begin{tabular}{clcc}
\hline \hline & \multicolumn{3}{c}{ RMSE } \\
\cline { 2 - 4 } Rute & ARIMA & $\begin{array}{c}\text { Regresi } \\
\text { Time Series }\end{array}$ & TBATS \\
\hline Denpasar & 4905 & 5144 & 4019 \\
Jakarta SH & 15266 & 12755 & 15180 \\
Balikpapan & 8214 & 10699 & 6074 \\
Makasar & 4942 & 5270 & 5726 \\
Banjarmasin & 5182 & 6799 & 7526 \\
Kupang & 1771 & 1748 & 2595 \\
Batam & 1733 & 2026 & 2734 \\
Bandung & 2372 & 15649 & 3314 \\
Yogyakarta & 1109 & 1692 & 1511 \\
Semarang & 947 & 1304 & 2118 \\
\hline \hline
\end{tabular}

Tabel 2 menunjukkan bahwa rute Makasar, Banjarmasin, Batam, Bandung, Yogyakarta, dan Semarang lebih baik di modelkan menggunakan ARIMA. Rute Jakarta Soekarno Hatta dan Kupang lebih baik dimodelkan menggunakan Regresi Time Series. Rute Denpasar dan Balikpapan lebih baik dimodelkan menggunakan TBATS. Berikut ini perbandingan nilai RMSE pada rute keberangkatan penumpang domestik.

Tabel 3. Perbandingan Nilai RMSE pada Rute Keberangkatan Penumpang Domestik

\begin{tabular}{cccc}
\hline \hline & \multicolumn{3}{c}{ RMSE } \\
\cline { 2 - 4 } Rute & ARIMA & $\begin{array}{c}\text { Regresi Time } \\
\text { Series }\end{array}$ & TBATS \\
\hline Denpasar & 8925 & 7594 & 6282 \\
Jakarta SH & 15881 & 12966 & 18589 \\
Balikpapan & 12278 & 10334 & 10146 \\
Makasar & 3937 & 5401 & 8724 \\
Banjarmasin & 9470 & 11625 & 11250 \\
Kupang & 2555 & 2597 & 1671 \\
Batam & 2740 & 1293 & 3199 \\
Bandung & 3703 & 11492 & 5517 \\
Yogyakarta & 1785 & 2931 & 1977 \\
Semarang & 904 & 757 & 2304 \\
\hline \hline
\end{tabular}

Tabel 3 menunjukkan bahwa rute Makasar, Banjarmasin, Bandung, dan Yogyakarta lebih baik menggunakan model ARIMA. Rute Jakarta Soekarno Hatta, Batam dan Semarang lebih baik menggunakan model Regresi Time Series. Rute Denpasar, Kupang, dan Balikpapan lebih baik menggunakan metode TBATS.Berikut ini perbandingan nilai RMSE pada rute kedatangan penumpang internasional.

Tabel 4. Perbandingan Nilai RMSE pada Rute Kedatangan Penumpang Internasional

\begin{tabular}{llcl}
\hline & \multicolumn{3}{c}{ RMSE } \\
\cline { 2 - 4 } \multicolumn{1}{c}{ Rute } & ARIMA & $\begin{array}{c}\text { Regresi Time } \\
\text { Series }\end{array}$ & TBATS \\
\hline Kuala Lumpur & 7367 & 5067 & 7927 \\
Singapura & 4835 & 3853 & 3449 \\
Hong Kong & 1124 & 1134 & 1297 \\
Bandar Sri B & 275 & 307 & 327 \\
Taipei & 254 & 410 & 302 \\
\hline \hline
\end{tabular}

Tabel 4 menunjukkan bahwa ruterute Hong Kong, Bandar Sri Begawan dan Taipei lebih baik menggunakan model ARIMA. Rute Kuala Lumpur lebih baik menggunakan model Regresi Time Series. Rute Singapura lebih baik menggunakan model TBATS. Berikut ini perbandingan nilai RMSE pada rute keberangkatan penumpang internasional. 
Tabel 5. Perbandingan Nilai RMSE pada Rute Keberangkatan Penumpang Internasional

\begin{tabular}{lccc}
\hline \multirow{2}{*}{ Rute } & \multicolumn{3}{c}{ RMSE } \\
\cline { 2 - 4 } & ARIMA & $\begin{array}{c}\text { Regresi Time } \\
\text { Series }\end{array}$ & TBATS \\
\hline Kuala Lumpur & 3601 & 3182 & 4977 \\
Singapura & 4446 & 2744 & 3477 \\
Hong Kong & 1048 & 952 & 1495 \\
Bandar Sri B & 460 & 596 & 597 \\
Taipei & 618 & 763 & 558 \\
\hline
\end{tabular}

Tabel 5 menunjukkan bahwa rute Bandar Sri Begawan lebih baik menggunakan model ARIMA. Rute Kuala Lumpur, Singapura, dan Hong Kong lebih baik menggunakan model Regresi Time Series. Rute Taipei lebih baik menggunakan model TBATS. Model terbaik dari masing-masing data kedatangan dan keberangkatan penumpang baik rute domestik maupun internasional dapat diperoleh dengan cara yang sama. Untuk mengetahui kebaikan model dalam melakukan $k$-ramalan ke depan digunakan perhitungan adaptive MAPE. Berikut ini plot adaptive MAPE rute kedatangan Denpasar.

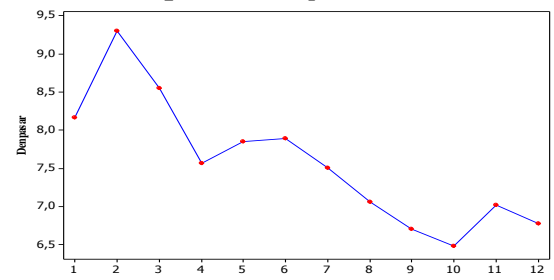

Gambar 3. Plot Adaptive MAPE Rute Kedatangan Denpasar

Gambar 3 menunjukkan bahwa data rute kedatangan penumpang Denpasar baik digunakan untuk meramalkan 12 periode ke depan. Plot adaptive MAPE untuk data lainnya dapat diperoleh dengan cara yang sama. Berdasarkan perhitungan keseluruhan rute, model untuk data kedatangan penumpang rute Jakarta Soekarno Hatta, Denpasar, Banjarmasin dan Kupang lebih baik digunakan untuk meramalkan 12 periode ke depan. Rute Balikpapan lebih baik digunakan untuk meramalkan 5 periode ke depan. Rute Makasar lebih baik digunakan untuk meramalkan 5 periode ke depan. Rute Semarang lebih baik digunakan untuk meramalkan 3 periode ke depan. Rute Batam, Bandung, dan Yogyakarta lebih baik digunakan untuk meramalkan 1 periode ke depan.

Model data keberangkatan penumpang rute Kupang lebih baik digunakan untuk meramalkan 12 periode ke depan. Rute Denpasar dan Balikpapan lebih baik digunakan untuk meramalkan 6 periode ke depan. Rute Semarang lebih baik digunakan untuk meramalkan 5 periode ke depan. Rute Makasar lebih baik digunakan untuk meramalkan 2 periode ke depan. Rute Jakarta Soekarno Hatta, Banjarmasin, Batam, Bandung, dan Yogyakarta lebih baik digunakan untuk meramalkan 1 periode ke depan. Model untuk data kedatangan penumpang rute Singapura, Hong Kong, Bandar Sri Begawan dan Taipei lebih baik digunakan untuk meramalkan 12 periode ke depan. Sedangkan rute Kuala Lumpur lebih baik digunakan untuk meramalkan 8 periode ke depan. Model untuk data keberangkatan penumpang rute Singapura, Hong Kong dan Taipei lebih baik digunakan untuk meramalkan 2 periode ke depan. Rute Bandar Sri Begawan lebih baik digunakan untuk meramalkan 8 periode ke depan. Sedangkan rute Kuala Lumpur lebih baik digunakan untuk meramalkan 1 periode ke depan.

Setelah mendapatkan model terbaik tahap selanjutnya adalah melakukan peramalan untuk data kedatangan dan keberangkatan penumpang baik rute domestik maupun internasional pada bulan Januari hingga Desember 2016. Didapatkan hasil jumlah penumpang tertinggi pada data kedatangan penumpang domestik rute Denpasar, Jakarta Soekarno Hatta, Balikpapan, Kupang, dan Semarang terjadi pada bulan Desember. Jumlah penumpang tertinggi pada rute Makasar dan Banjarmasin terjadi pada bulan Juli. Jumlah 
penumpang tertinggi pada rute Bandung dan Yogyakarta terjadi pada bulan Februari. Sedangkan jumlah penumpang pada rute batam pada semua bulan sama. Jumlah penumpang tertinggi pada data keberangkatan penumpang domestik rute Denpasar dan Semarang terjadi pada bulan Desember. Jumlah penumpang tertinggi pada rute Jakarta SH dan Batam terjadi pada bulan Juli. Jumlah penumpang tertinggi pada rute Makasar dan Banjarmasin terjadi pada bulan Agustus. Jumlah penumpang tertinggi pada rute Balikpapan terjadi pada bulan Oktober. Jumlah penumpang tertinggi pada rute Kupang terjadi pada bulan November. Sedangkan jumlah penumpang pada rute Bandung sama.

Jumlah penumpang tertinggi pada data kedatangan penumpang internasional rute Singapura, Hong Kong, dan Bandar Sri Begawan terjadi pada bulan Juli. Jumlah penumpang tertinggi pada rute Kuala Lumpur terjadi pada bulan Agustus. Jumlah penumpang tertinggi pada rute Taipei terjadi pada bulan Januari. Jumlah penumpang tertinggi pada data keberangkatan penumpang internasional rute Singapura terjadi pada bulan Juli. Sedangkan Jumlah penumpang tertinggi pada rute Kuala Lumpur, Hong Kong, Bandar Sri Begawan dan Taipei secara berurut urut terjadi pada bulan November, Juni, April dan Agustus.

\section{SIMPULAN DAN SARAN}

Berdasarkan hasil analisis dan pembahasan dapat ditarik beberapa kesimpulan sebagai berikut. Empat karakteristik kondisi existing penumpang menunjukkan bahwa ada beberapa rute yang tidak bisa menggunakan data out-sample data pada tahun 2014 dan 2015. Karena hampir di seluruh rute baik rute domestik maupun internasional jumlah penumpang pada tahun 2014 dan 2015 mengalami penurunan yang cukup signifikan. Salah satu penurunan tersebut dikarenakan adanya gunung meletus di tahun 2014 dan 2015.

Berdasarkan ketiga model hasil peramalan dari 30 data jumlah penumpang di Bandara Internasional Juanda diperoleh hasil bahwa Model terbaik dengan menggunakan model ARIMA terdapat 14 rute yaitu rute kedatangan Makasar, Banjarmasin, Batam, Bandung, Yogyakarta, Semarang, Hong Kong, Bandar Sri Begawan, Taipei dan rute keberangkatan Makasar, Banjarmasin, Bandung, Yogyakarta dan Bandar Sri Begawan. Model terbaik dengan menggunakan model Regresi Time Series terdapat 9 rute yaitu rute kedatangan Jakarta SH, Kupang, Kuala Lumpur dan rute keberangkatan Jakarta SH, Batam, Semarang, Kuala Lumpur, Singapura, dan Hong Kong. Sedangkan model terbaik dengan menggunakan model TBATS terdapat 7 rute yaitu rute kedatangan Denpasar, Balikpapan, Singapura dan rute keberangkatan Denpasar, Balikpapan, Kupang, dan Taipei. Saran yang diberikan untuk penelitian selanjutnya adalah lebih teliti lagi dalam pemilihan data insample dan out-sample. Karena apabila terjadi kesalahan dalam pemilihan data in-sample dan out-sampleakan menghasilkan nilai ramalan yang jelek. Pada metode ARIMA dan TBATS lebih baik jika ditambahi variasi kalender pada bulan terjadinya Hari Raya Idul Fitri agar mendapatkan hasil ramalan yang lebih baik.

\section{REFERENSI}

Aczel, A. D., \& Sounderpandian, J. (2008). Complete Business Statistics. United States of America: The McGraw-Hill Companies.

Airports Council Internasional. (2014). Airport Service Quality Awards 2014. Retrieved from http://www.aci.aero/Airport-Service-Quality/ASQ-Awards/PastWinners/2014.

Alin, O., Mihai, Țichindelean, Marieta, M. D., \& Cosmin, T. (2019). Forecasting Passenger 
Traffic for a Regional Airport. Studies in Business and Economics, 14(2), 105-114. Retrieved from https://content.sciendo.com/configurable/contentpage/journals $\$ 002$ fsbe $\$ 002 \mathrm{f} 14$ \$002f2\$002farticle-p105.xml

Bowerman, B. L., \& O'Connell, R. T. (1993). Forecasting and Time Series (Third Edit). California: Duxbury Press.

Cryer, J. D., \& Chan, K. (2008). Time Series Analysis: With Application in R. New York: Springer Science+Business Media.

Daniel, W. W. (2000). Daniel, W. W (D. Press., Ed.). Boston.

Kusumawati, F. A. (2015). Pemodelan Beban Listrik Jawa-Bali dengan Menggunakan Pendekatan Flexible Seasonality Forecasting. Institut Teknologi Sepuluh Nopember.

Lee, M. H., Suhartono, \& Hamzah, N. A. (2010). Calendar Variation Model Based on ARIMAX for Forecasting Sales Data with Ramadhan Effect. Regional Conference on Statistical Science. Retrieved from https://www.semanticscholar.org/paper/Calendar-variation-model-based-onARIMAX-for-sales-Lee-Hamzah/bd60d8a7e673356b4725b4d6f552a3f3a44bc073

Livera, A. M., Hyndman, R. J., \& Snyder, R. D. (2011). Forecasting Time Series with Complex Seasonal Patterns Using Exponential Smoothing. Journal of the American Statistical Association, 106(496). doi: https://doi.org/10.1198/jasa.2011.tm09771

Makridakis, S., \& Hibon, M. (2000). The M-3 Competition: Result, Conclusions and Implications. International Journal of Forecasting, 16(4), 451-576. doi: https://doi.org/10.1016/S0169-2070(00)00057-1

Suryani, E., Chou, S., \& Chen, C. (2010). Air Passenger Demand Forecasting and Passenger Terminal Capacity Expansion: A System Dynamic Framework. Expert System with Applications, 37, 2324-2339.

The Guide to Sleeping in Airports. (2016). Best Airports in Asia 2015. Retrieved from http://www.sleepinginairports.net/2015/best-airports-asia.htm.

Tsui, W. H. K., Balli, H. O., Gilbey, A., \& Gow, H. (2014). Forecasting of Hong Kong Airport's Passenger Throughput. Tourism Management, 42(3), 62-76.

Wei, W. S. (2006). Time Series Analysis Univariate and Multivariate Methods (Second Edi). New York: Pearson Addison Wesley.

Wulandari, N., Setiawan, S., \& Ahmad, I. S. (2016). Peramalan Inflasi Kota Surabaya dengan Pendekatan ARIMA, Variasi Kalender dan Intervensi. Jurnal Sains and Seni ITS., 5(1), 90-95. doi: 10.12962/j23373520.v5i1.14693.

Xie, G., Wang, S., \& Lai, K. K. (2014). Short-term Forecasting of Air Passenger by Using Hybrid Seasonal Decomposition and Least Squares Support Vector Regression Approaches. Journal of Air Transport Management, 37(2), 20-26. 